Revista de la red interuniversitaria de estudios sobre las literaturas rioplatenses contemporáneas en Francia

$11 \mid 2014$

De niños e infancias

\title{
Un conejo
}

Pedro Mairal

\section{OpenEdition}

Journals

\section{Edición electrónica}

URL: http://journals.openedition.org/lirico/1771

DOI: $10.4000 /$ lirico. 1771

ISSN: 2262-8339

Editor

Réseau interuniversitaire d'étude des littératures contemporaines du Río de la Plata

Referencia electrónica

Pedro Mairal, « Un conejo », Cuadernos LIRICO [En línea], 11 | 2014, Puesto en línea el 01 diciembre 2014, consultado el 01 mayo 2019. URL : http://journals.openedition.org/lirico/1771 ; DOI : 10.4000/ lirico. 1771

Este documento fue generado automáticamente el 1 mayo 2019.

\section{(c) $(1) \Theta \Theta$}

Cuadernos LIRICO está distribuido bajo una Licencia Creative Commons Atribución-NoComercialSinDerivar 4.0 Internacional. 


\title{
Un conejo
}

\author{
Pedro Mairal
}

\section{NOTA DEL EDITOR}

Pedro Mairal (Buenos Aires, 1970). Su novela Una noche con Sabrina Love recibió el Premio Clarín de Novela en 1998 y fue llevada al cine en 2000. Publicó además las novelas El año del desierto (Interzona, 2005) y Salvatierra (Emecé, 2008) ; un volumen de cuentos, Hoy temprano (Clarin Aguilar, 2001) ; y dos libros de poesía, Tigre como los pájaros (Botella al mar, 1996) y Consumidor final (Bajo la luna, 2003). En 2011 condujo el programa de televisión sobre libros "Impreso en Argentina". En 2013 publicó El gran surubí (Orsai, 2013) , una novela en sonetos, y El equilibrio (Garrincha, 2013), una recopilación de sus columnas.

\section{Un conejo}

1 Yo sé muy bien lo que es morir. Porque una vez me quedé a dormir en lo de mi amigo Gonzalo Helidas y estuvimos jugando el sábado con su conejo nuevo, un conejo blanco, chiquito, y a la mañana siguiente yo me desperté más temprano que todos y fui al lavadero, al lado de la cocina, a jugar con el conejo, y cuando lo toqué no se movía. Estaba duro adentro de la caja. Entonces me di cuenta de que estaba muerto y pensé que me iban a echar la culpa a mí. Preferí no decir nada y dejar que lo descubrieran solos, cuando se despertaran. Fueron apareciendo todos con cara de dormidos y desayunamos sentados, el papá de Gonzalo leyendo el diario en pijama, la mamá haciendo tostadas, Gonzalo y el hermano más grande peleándose por algo que no me acuerdo, y yo untando mi pan en silencio, sabiendo que el conejo estaba muerto, preguntándome qué iba a pasar, qué había que hacer en estos casos y quién tenía la culpa. ¿Había sido yo o era culpa de todos ? Quizá la tarde anterior en el jardín lo habíamos cansado demasiado cuando lo perseguimos entre las plantas alrededor de la pileta, quizá lo apretamos mucho cuando nos tirábamos palomita para agarrarlo, o la manteada que le hicimos con un suéter... Quizá se mareó y se 
descompuso y vomitó la zanahoria con lechuga y se murió. Pensaba que iba a haber un funeral para el conejo y Gonzalo iba a llorar y el hermano también. Estaba esperando que alguien se diera cuenta y de repente Gonzalo dijo "Ah, mi conejo" y corrió hasta el lavadero. Yo me quedé sin morder la tostada para no hacer ruido y no perderme nada. De repente se escuchó "¡Uy, este también se murió, Má!". "Peeeero", dijo la madre y mirándolo al papá de Gonzalo, que no dejaba de leer el diario, dijo "No vayas más a esa veterinaria que nos encajan siempre bichos defectuosos, Raúl". Yo me levanté y me hice el sorprendido. También vino el hermano más grande de Gonzalo y levantó el conejo con una bolsa. Yo le dije a Gonzalo que lo teníamos que enterrar en el jardín, y a él le gustó la idea ; quería hacer una tumba y una cruz hecha con palitos de helado. Pero el hermano le hizo un nudo a la bolsa con el conejo muerto adentro, salió al jardín y la revoleó sobre el paredón al baldío vecino. Así nomás. Se escuchó que la bolsa caía del otro lado, entre los yuyos. Gonzalo no protestó mucho, incluso se rió un poco.

\section{Jardín de infantes}

2 Mamá me lleva al jardín y me da un jarabe envuelto en papel madera. Me lo da con una nota para la maestra. En el auto le digo que no quiero tomarlo ; me dice que lo tengo que tomar ¿Por qué lo tengo que tomar? Porque sí. No lo quiero tomar, ¿por qué lo tengo que tomar?, mamá se harta y me dice : porque si no lo tomás te morís. Entro al jardín. Es demasiado temprano. Todavía está oscuro y no hay nadie en el patio. Me trepo a uno de esos caballetes para hacer gimnasia. Llega otro chico y también se trepa. Estamos jugando y el frasco de jarabe se me escapa de la mano, se resbala del envoltorio de papel, se va al suelo, no lo veo caer, pero escucho que se hace pedazos sobre el piso del patio. Un piso de cemento con agujeritos cuadrados. Ahí está el jarabe desparramado y los vidrios rotos. Empiezo a llorar. Una maestra me lleva para adentro y trata de calmarme y me dice que no me preocupe, pero es muy difícil calmarte o no preocuparte cuando sabés que te vas a morir porque se te rompió en el suelo el frasco del remedio que tenías que tomar para no morirte y no hay solución, un frasco de vidrio roto no se arregla y mamá ya se fue y acá estoy entre toda esta gente que me mira y no sabe que yo dentro de un rato me voy a morir.

\section{Campamento en Mashwitz}

Está todo primer y segundo grado levantando campamento, haciendo las mochilas. Se acabó el fin de semana en Maschwitz, el primer campamento de nuestra vida. Acampamos junto a un lago, bajo unos eucaliptus; el suelo está cubierto de esas hojas curvas, verdes, amarillas y rosadas. Tuvimos que traer una lista de cosas : bolsa de dormir, linterna, coy, mugo enlosado, cantimplora, repelente para insectos, brújula, soga de diez metros. Fue muy divertido desplegar todo ese arsenal durante el fin de semana, pero ahora hay que intentar guardarlo y sobran cosas que quedaron desparramadas, sin dueño. El Gómez, que es profesor de educación física y cuando se enoja se le estira el bigote, está pasando uno por uno ayudando a armar bien las mochilas. Yo anoche me hice pis en la bolsa de dormir. Nadie lo sabe. El Gómez desarma las mochilas que están mal armadas y las arma de nuevo. Desenrolla la bolsa de dormir en la luz pública y la vuelve a enrollar. Eso es malo, porque se va a notar mi pis. 
4 Anoche traté de concentrarme en no hacerme pis pero me olvidé. En algún momento me quedé dormido sin acordarme de eso, porque estábamos divertidos con el Vaca y Crespo y Miguel por la novedad de dormir en carpa : probábamos las linternas, lo iluminábamos en la cara a Fidalgo mientras dormía, hablábamos mal de él, hasta que dijo "estoy despierto y escuché todo", y nos reímos más todavía. Entonces en algún momento me dormí sin acordarme y a la mañana sentí que estaba mojado y recé para que fuera sudor pero no era, y encima se notaba. Yo sé que hay cosas más graves, que a otros les pasaron cosas peores. Por ejemplo Diego Larroque casi se muere ahorcado con la soga de diez metros de nailon plastificada cuando jugaba con Rosemberg a las ejecuciones; pataleó un poco y el profesor Inchauspe corrió y lo salvó. O Teibal y Giménez que se perdieron porque se fueron lejos para probar la brújula. O Manfredi que se clavó un anzuelo en el dedo y se lo tuvieron que sacar los choferes del ómnibus con una tenaza. Pero eso no me consuela. Igual la cosa para mí es grave, no me gusta.

Trato de armar bien la mochila, para que el Gómez no me la desarme pero no puedo, me sobran puntas de cosas, lo que estaba antes bien doblado ahora es un bollo que ocupa el triple de lugar y no entra. El Gómez ya está con Aguirre, al lado mío. El próximo voy a ser yo. La mochila de Aguirre está bastante mal, y el Gómez se la desarma. Cuando está tratando de enrollar la bolsa de dormir, ve un círculo oscuro. Yo también lo veo y me sorprende que Aguirre pertenezca a la misma hermandad secreta. El Gómez huele el círculo oscuro y le dice "¿Te hiciste pis ?". Aguirre apenas asiente con la cabeza, como diciendo "Sí, pero mantengámoslo entre nosotros". "Esto hay que secarlo", dice el Gómez y con toda naturalidad, sin siquiera sospechar que está traumatizando de por vida a mi pobre camarada, cuelga la bolsa de la rama de un árbol. Las risas empiezan a crecer, la bolsa de dormir flamea en la rama con el círculo oscuro en el medio : es la bandera de los incontinentes.

6 Yo aprovecho el revuelo para agarrar mis cosas y caminar como si buscara algo. "Me olvidé la cantimplora en el lago", digo en voz alta aunque nadie me está oyendo. Camino hacia la orilla, saco la cantimplora y, con la mochila a la espalda, agarrada con una sola tira, me pongo a llenarla. El movimiento me sale bien: un resbalón común, bastante posible, y la mochila está en el agua. La demora en sacarla también es creíble, porque está totalmente ensopada y muy pesada. Es un triunfo absoluto, y por eso aguanto muy bien las burlas, incluso afronto sin problemas el reto del Gómez que me hace sacar todo y desplegarlo sobre el pasto. Lo hago con tranquilidad, ocultando la sonrisa porque está todo igual de mojado y oscuro. Mi bandera de pis no se nota para nada y pienso que ojalá, cada vez que voy a dormir a la casa de un amigo, pudiera a la mañana siguiente inundar la habitación abriendo todas las canillas o sumergir la casa en el fondo del mar o algo así, para evitar esa evidencia terrible de los colchones mojados secándose al sol.

\section{Departamentos}

\section{I}

7 Cuando llegamos al departamento de la amiga de mamá, me mandaron a jugar al cuarto de la hija. Empecé a abrir la puerta y oí una voz que decía "Vení, vení". La vi arrodillada en medio de un cuarto todo empapelado con una de esas fotos de un bosque en otoño. Me acerqué despacio porque en la alfombra verde había hojas secas desparramadas. Quedamos frente a frente, sentados sobre los talones. Ella era narigona. “¿A qué 
jugamos ?", me preguntó. En el aire parecía sonar una grabación de pajaritos. El único mueble era una cama de troncos. "No sé", le dije. Había ramas en el suelo. "Entonces juguemos a que vos me matabas". Yo me levanté, agarré una rama y le empecé a pegar en la cara. La rama era también un atizador. Ella no se defendió, no gritó. Los golpes eran blandos, pero la lastimaban. Le pegué en la cabeza y en la cara, y ella cayó lánguida sobre el colchón de hojas. Entre el pelo castaño, desparramado sobre las hojas, corría un arroyito de sangre con una melodía, con un murmullo. Quedó en el piso, con los ojos abiertos, fulminada por la belleza de su propia muerte. Durante un rato no pude dejar de mirarla. Escuché que me llamaban. Solté la rama y me alejé caminando entre los árboles del bosque.

II

8 Ni mis hermanas ni yo teníamos agua en casa y fuimos a bañarnos a "Austria", como le decíamos al departamento que quedaba en esa calle y que había sido de mi abuela. Yo tenía las llaves. Primero había vivido ahí mi hermana mayor, después mi hermana menor, después yo. Eran muchas llaves : la de la puerta de calle, chata y grande como con dos aspas; la de la puerta del ascensor en el sexto piso, especial, dentada, de puerta blindada, que hacía mucho ruido y a veces se trababa ; y por último la del palier, una Trábex común. Cuando entramos, vi que había muebles viejos. Mi hermana mayor se fue a prender la ducha. Yo nunca había visto esos sillones verdes, esa mesa ratona con las patas arañadas, mordidas. De pronto me acordé : habíamos vendido el departamento hacía unos meses. Lo había comprado una señora con un rottweiler. Yo no vivía más ahí. Teníamos que irnos. No entendía cómo podía haberme olvidado de eso. Le dije a mi hermana que nos fuéramos. Mi otra hermana apareció en toalla, riéndose. Las dos se reían, me decían : "No seas cagón, no pasa nada". Pero teníamos que irnos. En cualquier momento iba a llegar la señora. Yo la había visto el día de la escritura : de unos setenta años, petisa, con pelo corto teñido de naranja, ojos azules; era viuda y hablaba mucho de su perro. Vivía sola con él. Le dije a mi hermana que se vistiera. No podíamos quedarnos ni un segundo más. Me enojé con ellas. No me hacían caso. Entonces escuché ruidos en la puerta. La señora estaba llegando. Abrí la puerta del palier para explicarle. Ella trataba de abrir la puerta del ascensor que a veces se trababa. Espié por la mirilla. Quedé a oscuras en el palier. Escuché el gruñido. Ella se dio cuenta de que había alguien del otro lado, dentro de su casa. Le vi el miedo en la mirada. “¿Quién es ?”, preguntó. Mis hermanas parecían ya no estar conmigo. Quise hablar, explicarle antes de que abriera la puerta, pero no podía, me salió de la garganta una especie de gruñido, quise gritar mi nombre y me salió un ladrido fuerte, monstruoso. 